\title{
Treating Urge Incontinence in Older Women: A Cost-Effective Investment in Quality-Adjusted Life-Years (QALY)
}

\author{
Victoria L. Phillips, ${ }^{1}$ Ali Bonakdar Tehrani, ${ }^{2}$ Holly Langmuir, ${ }^{3}$ \\ Patricia S. Goode, ${ }^{4,5}$ and Kathryn L. Burgio ${ }^{4,5}$ \\ ${ }^{1}$ Department of Health Policy and Management, Rollins School of Public Health, Emory University, Atlanta, GA 30322, USA \\ ${ }^{2}$ Department of Healthcare Policy and Research, School of Medicine, Virginia Commonwealth University, Richmond, VA 23298, USA \\ ${ }^{3}$ Crozer Chester Medical Center, Upland, PA 19013, USA \\ ${ }^{4}$ Birmingham/Atlanta Veterans Affairs Geriatric Research, Education, and Clinical Center, Birmingham, AL 35233, USA \\ ${ }^{5}$ Department of Medicine, University of Alabama at Birmingham, Birmingham, AL 35294, USA
}

Correspondence should be addressed to Victoria L. Phillips; vphil01@sph.emory.edu

Received 6 November 2014; Accepted 16 January 2015

Academic Editor: Ian Stuart-Hamilton

Copyright (C) 2015 Victoria L. Phillips et al. This is an open access article distributed under the Creative Commons Attribution License, which permits unrestricted use, distribution, and reproduction in any medium, provided the original work is properly cited.

Objectives. To conduct cost-effectiveness analyses of urge incontinence treatments for older women. Methods. Decision-analytic models assessed three treatment pathways: (1) limited behavioral therapy (LBT); (2) full behavioral therapy (FBT) with biofeedback; and (3) drug (DRUG), with allowances for crossover options following initial treatments. Model inputs were gathered from published data. Cost data were based on third party payer reimbursement. Outcomes were measured as the number of incontinence episodes avoided and quality-adjusted life years gained (QALYs). Results. At baseline values costs per QALY gained ranged from US\$3696 to \$10609. LBT was the least costly with the lowest benefit. Switching from LBT to FBT, with the greatest gain, was \$415 per additional QALY. DRUG was the most expensive option. Sensitivity analyses showed that only small changes in key inputs were required for DRUG to generate greater gains than FBT. Medication costs had to fall substantially for DRUG to be cost competitive. Conclusion. All treatment strategies provide QALYs gains at a bargain price, compared to the standard of US\$50,000 per QALY gained. No single treatment strategy dominated under all conditions. Clinicians should offer multiple treatment options to older women with urge incontinence.

\section{Introduction}

Urge incontinence, the involuntary loss of urine associated with a strong desire to void, affects $30 \%$ of women over the age of 40 in Sweden, the UK, and the US [1], is a risk factor for depression, and negatively impacts quality of life [2]. In spite of treatment availability, multiple sources suggest that incontinent older women do not receive any treatment, and when they do, it is often after years of suffering [3]. Both the European Association of Urology (EAU) and the American Urological Association (AUA) recommend conservative treatment $[4,5]$, namely, behavioral and pharmacological options, with the former preferred in the US. Data on the relative use of interventions are not available and the treatment modality pursued likely depends on several factors [6].

Drugs reach their maximum effectiveness more quickly than behavioral interventions, but are often discontinued due to side-effects and drug costs. Extended-release formulations, with lower side-effect rates compared to immediate-release compounds, may increase drug adherence [7]. Patients, however, may prefer to avoid long-term drug use and/or adding another drug to their regimen, especially if behavioral treatments are available.

Behavioral treatments usually contain multiple components, such as urge control strategies, pelvic floor muscle training, and/or scheduled toileting [8]. Training commonly 
involves biofeedback or vaginal palpation. Behavioral therapies are options for patients who are cognitively capable of learning new skills and are willing to commit to exercising their pelvic floor muscles on a daily basis.

Determining which treatment approach is best depends on clinician judgment and patient-specific factors. Considerations include the severity of the incontinence, goals for treatment outcomes, number of doctor visits, time to perform exercises, preferences regarding use or nonuse of medication, and drug costs.

This paper uses a decision analytic model to examine treatments for urge incontinence for older women. The three treatment options considered, alone and in combination, were FBT, LBT, and DRUG. They were selected because they have been well-studied and have proven to be effective, but not decisively so relative to each $[4,9]$. They also represent approaches from geriatrics, primary care, urology, and gynecology, all specialties likely to offer treatment, and are common across countries [10].

Treatment outcomes were measured in terms of episodes of incontinence avoided and quality-adjusted life years (QALYs); the latter allows cost-effective comparisons with other treatments and to a common cost-effectiveness standard. The costs and benefits of the pathways were calculated at baseline input values. Treatments were ranked by increasing costs and were compared to no treatment and then the next most expensive treatment to determine the cost per additional health benefit. Given that results in practice settings are likely to differ from those in controlled trials, baseline model inputs were varied in sensitivity analyses to identify over what ranges and conditions the preferred strategy changes.

\section{Methods}

Each single treatment was followed by a crossover option where a patient could (1) discontinue treatment; (2) continue the monotherapy; (3) choose another option altogether; or (4) add a therapy to the current one. Patients could also drop out of initial therapy prior to completion as well as the revised therapy following crossover. All pathways represent documented choices by patients in RCTs. Model inputs were drawn from the published literature.

Direct treatment costs and effects, incontinence episodes avoided per week and quality-adjusted life years (QALYs) gained, were calculated based on patients progressions through treatment pathways. The decision tree was constructed using TreeAge Pro 2009 (TreeAge Software Inc, Williamstown, MA, USA) and evaluated for a twelve-month period. One and two-way sensitivity analyses related to cost and effectiveness were conducted on key model inputs to simulate conditions in clinical settings. Probabilistic sensitivity analyses around mean reduction in episodes and percent experiencing complete remission were used to generate standard deviations.

2.1. Treatment Options and Models. Data from the peer reviewed literature were used to populate the input values. Effects and costs of the two behavioral therapies, as well as combined drug and behavioral therapy, were drawn from three published RCTs which followed clearly defined behavioral protocols and focused on urge incontinence in older women [11, 12, 21]. Both included pelvic floor muscle training, education around urge control strategies, and selfmonitoring with bladder diaries. FBT included biofeedback for muscle training, while LBT used vaginal palpation. Both strategies involved an initial physician visit and four followup visits with a nurse practitioner (NP) with physician oversight.

Average values from RCT studies on six medications were used as inputs related to DRUG. Both US and European analyses have concluded that no drug is consistently more effective than another $[5,7,22]$ and the focus here is pharmacological versus behavioral approaches, not on comparison of individual drugs. The drug treatments reviewed were extended-release tolterodine, extended-release oxybutynin, trospium, solifenacin, darifenacin, and fesoterodine; all have been studied extensively for the treatment of incontinence $[13,14,23-27]$.

Figure 1 shows the treatment pathway for FBT for illustration; the other two treatments follow the same model. Treatment sequences are as follows. After beginning an initial monotherapy, a patient could stop treatment (withdraw) at week four or continue. Those who continued therapy experienced one of three outcomes by week twelve: complete remission, a reduction in episodes, or no effect from treatment. Those experiencing complete remission were assumed to remain on the current therapy for either six or twelve months, depending on their willingness to continue therapy.

Patients on the other two branches (i.e., those experiencing only some reduction or no effect) were assumed to discontinue treatment at week twelve or continue therapy. Those continuing therapy could (1) maintain treatment; (2) switch treatments; or (3) add a therapy, such as DRUG to LBT or FBT. Any dropout for the revised strategy was assumed to occur at week sixteen. Those continuing were assumed to remain on therapy for either six months or twelve months. The complete model is available from the authors.

All initial treatment intervals were assumed to be eight weeks. Each treatment involved an initial physician visit. For FBT and LBT, the four subsequent visits for behavioral training were assumed to be with a NP with physician oversight. For those on DRUG, any dose change visit required was assumed to occur at week eight. One physician visit was also required for all arms for treatment review at week 16. Patients accumulated costs and any benefits up to the point where they discontinued therapy or at the end of six or twelve months.

2.2. Input Values. Model input data included values for the percent: who withdrew from treatment; who experienced complete remission, a reduction in episodes, or no effect for each treatment; who changed treatment, who required medication dose changes, and who experienced side-effects. Key input probabilities and sources are provided in Table 1. Where two values from separate trials were available, the midpoint of the values was used. For example, two studies of 


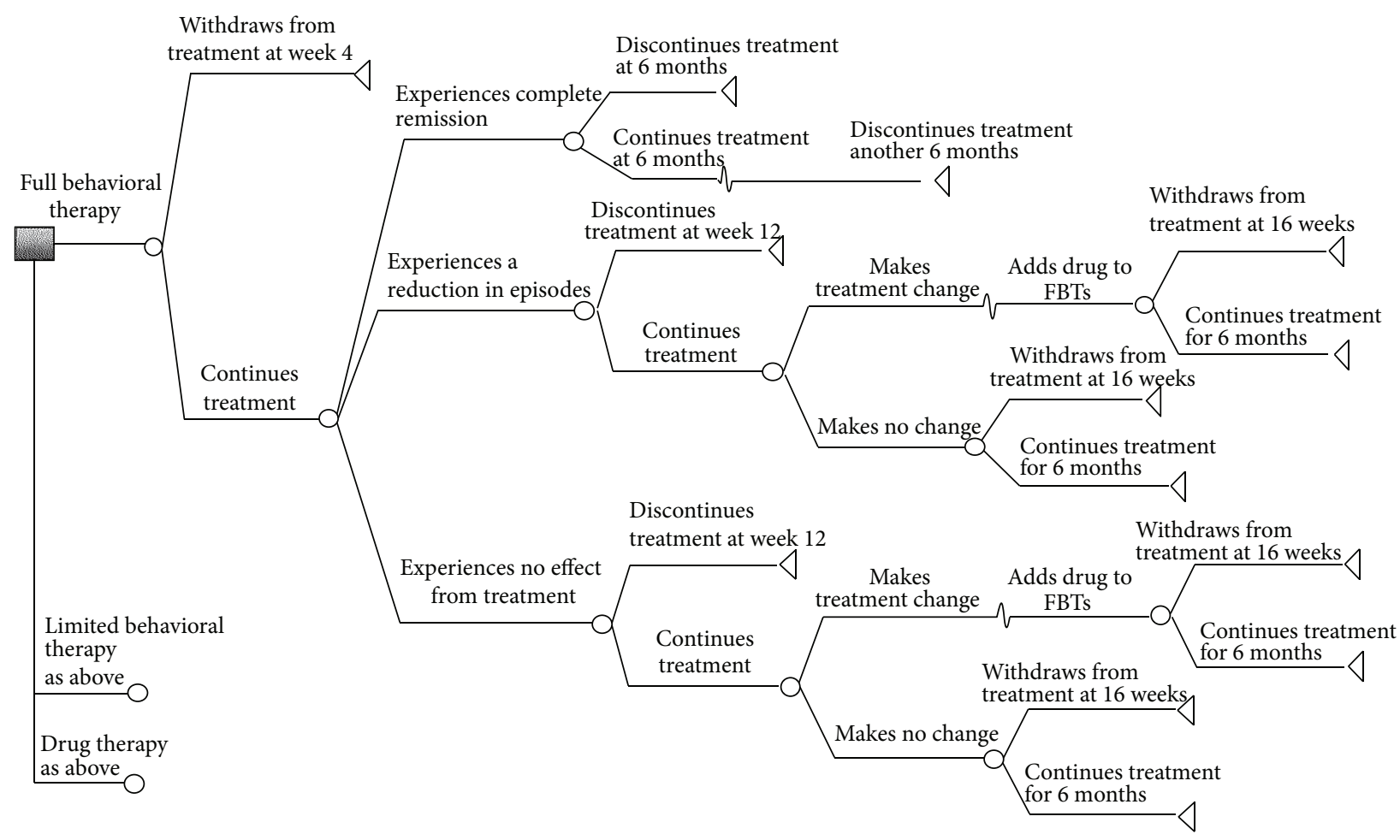

FIGURE 1: Full behavioral therapy (FBT) branch of urge urinary incontinence treatment decision tree.

FBT provide different estimates, $63 \%$ and $81 \%$, respectively, for the mean reduction in incontinence episodes [12, 21]; the input value used was $72 \%$.

For the purposes of calculating incontinence episodes avoided, complete remission was defined as avoiding 15 episodes per week, which is the mean number of episodes experienced by most populations included in the clinical trials for women, cited here, prior to treatment [12]. If therapy is ineffective, zero episodes are avoided. For the partial response group, episodes avoided were equal to the average reduction in episodes, for those experiencing some reduction, multiplied by 15 .

The Quality of Well-Being Scale (QWB) version 7.0 [15] was used to calculate QALYs, based on the number of incontinent episodes occurring per week. The instrument is widely used to calculate QALYs and recommended as an instrument of choice by the US Medical Outcomes Trust. One key symptom included in the QWB is "problems related to or with urination weekly" and the number of incontinent episodes experienced by a patient determines the QWB score.

An individual without incontinence would experience no QALY loss, while women who experienced daily problems would have a score of 0.708 , or the equivalent of a loss of three and a half months of quality life per year due to incontinence. The QWB algorithm is not linear, so no gain in QALYs occurs until incontinent episodes are reduced to fewer than six per week, or less than half of the baseline value of 15. Medication side-effects, such as constipation, dry mouth, and blurred vision, were assumed to reduce QALY gains; the calculation was based on the symptom weights in the QWB algorithm.
The percent of patients experiencing medication side-effects was subject to sensitivity analysis.

Reimbursement rates, based on procedure codes, from the US national health insurance program for the elderly, known as Medicare, were used to cost physician and NP visits, along with procedure costs. 2012 values are provided on the Medicare website (http://www.cms.gov). The physician visit cost for initiating treatment was US\$73, while visits for altering treatment or initiating a dose change cost US $\$ 28$. NP visits for behavioral treatments were US $\$ 48$. Monthly medication costs were US\$106, the generic price for extended-release OXY [22].

The analyses omit a number of costs included in other studies [10]. Patients were assumed to continue to use pads as before, in spite of any treatment effects. Clinical experience has shown even more successfully treated have a lag-time before they are willing to go without pads and some avoid the risk altogether [16]. Productivity losses associated with treatment were not included given the age of patients and the fact that any income losses due to time spent in treatment and/or completing exercises for $\sim 15$ minutes three times per day were likely to be minimal. Also, they were unlikely to differ significantly across treatment arms, given the option of combination strategies. Note that the omissions are likely to offset each other. Reductions in pad costs underestimate savings to the patient, while ignoring indirect costs overestimates savings. Patients were also assumed to be communitydwelling and able to care for themselves in terms of bladder issues; thus, caregiver burden is not included in the analyses. 
TABLE 1: Probabilities and sources for model inputs.

\begin{tabular}{|c|c|c|c|c|c|c|c|c|c|}
\hline $\begin{array}{l}\text { Treatment } \\
\text { strategies and } \\
\text { [sources] }\end{array}$ & $\begin{array}{c}\text { Withdrawal } \\
(\%)\end{array}$ & $\begin{array}{l}\text { Complete } \\
\text { remission } \\
(\%)\end{array}$ & $\begin{array}{l}\text { Reduction } \\
\text { in episodes } \\
(\%)\end{array}$ & $\begin{array}{c}\text { Therapy } \\
\text { ineffective } \\
(\%)\end{array}$ & $\begin{array}{l}\text { Mean } \\
\text { reduction in } \\
\text { episodes } \\
(\%)\end{array}$ & $\begin{array}{c}\text { Crossover } \\
\text { rate }(\%)\end{array}$ & $\begin{array}{c}\text { Dose } \\
\text { adjustment } \\
(\%)\end{array}$ & $\begin{array}{l}\text { Side effect } \\
(\%)\end{array}$ & $\begin{array}{l}\text { Continue } \\
\text { treatment to } \\
12 \text { months } \\
(\%)\end{array}$ \\
\hline $\begin{array}{l}\text { Full behavioral } \\
\text { therapy }[11,12]\end{array}$ & 11 & 24 & 73 & 3 & 72 & & - & - & 72 \\
\hline $\begin{array}{l}\text { Full behavioral } \\
\text { therapy in } \\
\text { combination } \\
\text { with drug } \\
\text { therapy [11] }\end{array}$ & & & & & 86 & 13 & & & \\
\hline $\begin{array}{l}\text { Limited } \\
\text { behavioral } \\
\text { therapy [12] }\end{array}$ & 15 & 17 & 74 & 9 & 57 & & - & - & 54 \\
\hline $\begin{array}{l}\text { Limited } \\
\text { behavioral } \\
\text { therapy with } \\
\text { change to full } \\
\text { behavioral } \\
\text { therapy [12] }\end{array}$ & & & & & 64 & 55 & & & \\
\hline $\begin{array}{l}\text { Limit behavioral } \\
\text { therapy with } \\
\text { change to drug } \\
\text { therapy [11] }\end{array}$ & & & & & 77 & 19 & & & \\
\hline $\begin{array}{l}\text { Average for } \\
\text { drug therapy }\end{array}$ & 9 & 26.5 & 67.5 & 6 & 60 & & 13 & 33 & 55 \\
\hline $\begin{array}{l}\text { Drug therapy } \\
\text { with change to }\end{array}$ & & & & & & 35 & & & \\
\hline $\begin{array}{l}\text { Full behavioral } \\
\text { therapy [12] }\end{array}$ & & & & & & 86 & & & \\
\hline
\end{tabular}

${ }^{1}$ References: [12, 17, 18, 21, 23-25, 27-29].

\section{Results}

Table 2 provides the total costs and outcomes associated with each strategy at baseline values and the incremental results from comparing strategies to each other. Figures in the first three rows are average costs or a comparison of each strategy to no treatment. LBT is the least costly strategy and produces the lowest level of benefit. DRUG is the most costly strategy and produces greater benefits than LBT, but less than FBT. FBT, with the greatest outcomes, costs 5\% more than LBT and over 2.5 times lower than that of DRUG. The outcomes ranged from $\$ 0.94$ to $\$ 2.54$ per episode avoided, while the cost per QALY gained ranged from \$3696 to \$10609.

The incremental values in the lower half of the table show how much is gained with a more expensive option. At baseline values, if FBT is pursued over LBT, benefits are gained at the cost of $\$ 0.32$ per episode and \$415 per QALY. Gains with DRUG compared to LBT are more costly at close to $\$ 13$ per episode and \$17424 per QALY gained. Moving from FBT to
DRUG increases cost by $\$ 558$ for a loss of eight episodes avoided and a loss of 0.008 QALYs, hence the negative signs.

Baseline model inputs were drawn from RCTs; therefore extensive sensitivity analyses were performed to identify how the results changed as input values changed, likely to be the case as treatments are implemented in practice. Key inputs values examined were (1) drug prices and FBT withdrawal rates on costs and (2) withdrawal rates, percent of patients experiencing remission, episodes avoided per strategy, the percent who continue on therapy after six months, percent experiencing side effects, and percent changing treatments by type of change on outcomes.

In terms of cost, drug prices need to decrease eightfold to $\$ 13$ per month for DRUG to become less costly than FBT and to $\$ 7$ per month for DRUG to be less costly than LBT. FBT becomes less costly than LBT only if the FBT withdrawal rate from treatment, a negative event, rises to $20 \%$ from a baseline of $11 \%$. 
TABLE 2: Yearly and incremental costs (US\$), episodes avoided, and quality-adjusted life years (QALYs) gained for each strategy with crossover and strategies compared to each other.

\begin{tabular}{|c|c|c|c|c|c|}
\hline Strategies with crossover & $\begin{array}{l}\text { Cost } \\
\text { (s.d.) }\end{array}$ & $\begin{array}{c}\text { Number of } \\
\text { incontinence episodes } \\
\text { avoided (s.d.) }\end{array}$ & QALY gain (s.d.) & $\begin{array}{l}\text { Average cost per } \\
\text { episode avoided }\end{array}$ & $\begin{array}{l}\text { Average cost } \\
\text { per QALY } \\
\text { gained }\end{array}$ \\
\hline \multicolumn{6}{|c|}{ Baseline values for each strategy } \\
\hline Limited behavioral & $323(22.9)$ & $308.7(115.6)$ & $0.051(0.007)$ & 1.05 & 6333 \\
\hline Full behavioral & $340(105.1)$ & $362(140.2)$ & $0.092(0.006)$ & 0.94 & 3696 \\
\hline \multirow[t]{2}{*}{ Drug therapy } & $898(277.2)$ & $354(123.8)$ & $0.084(0.002)$ & 2.54 & 10609 \\
\hline & $\begin{array}{l}\text { Incremental } \\
\text { costs } \\
\text { (s.d.) }\end{array}$ & $\begin{array}{c}\text { Incremental number } \\
\text { of incontinence } \\
\text { episodes avoided } \\
\text { (s.d.) }\end{array}$ & $\begin{array}{c}\text { Incremental } \\
\text { QALY gain (s.d.) }\end{array}$ & $\begin{array}{c}\text { Incremental cost } \\
\text { per episode } \\
\text { avoided }\end{array}$ & $\begin{array}{c}\text { Incremental } \\
\text { cost per } \\
\text { QALY } \\
\text { gained }^{1} \\
\end{array}$ \\
\hline
\end{tabular}

Full behavioral therapy to limited behavioral

therapy

Each strategy compared to a less costly strategy

Drug therapy to limited behavioral therapy

17 (25.2)

$53.3(71.8)$

0.041 (009)

0.32

415

Drug therapy to full behavioral therapy

$45.3(87.6)$

$0.032(.007)$

12.69

17,424

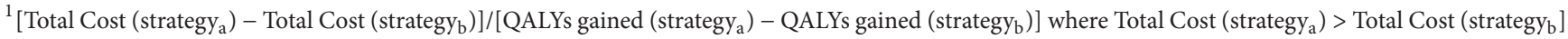
and strategy $\mathrm{y}_{\mathrm{a}}$ is first listed in the row.

${ }^{2}$ Drug has higher costs and lower outcomes than full behavioral therapy, so incremental values are negative, for example: row 6, column 5: (898 - 340)/(354 $362)=-69.75$ or paying more for a reduced outcome.

In terms of episodes avoided, small changes $(<10 \%)$ in input values are required to alter the preferred treatment. If withdrawal rates from DRUG treatment fall by $1.8 \%$ or more, DRUG is more effective than FBT. If withdrawal rates from FBT rise by $2 \%$, DRUG is preferred and if withdrawal from FBT rises by 7\%, LBT is preferred. If the complete remission rate for FBT falls by 6.5\%, DRUG is preferred. If the baseline number of episodes avoided with DRUG rises by 2.9 or falls for FBT by 0.8 , DRUG is preferred. If FBT effectiveness falls by 2.3 episodes avoided, LBT is preferred.

Figure 2 shows the ranges over which each strategy is preferred in terms of episodes avoided as the mean reduction in episodes avoided by FBT and DRUG are varied simultaneously. The lower left quadrant shows that at low levels of effectiveness for DRUG and FBT, LBT is preferred.

Larger changes $(>10 \%)$ in other values are required to alter the preferred strategy. If the rate for continuing therapy after six months for DRUG rises by $11 \%$ or if the rate of continuation for FBT falls by $12 \%$, DRUG is preferred. Finally, in terms of QALYs, if side-effects for DRUG fall to $10 \%$, DRUG is preferred to FBT. DRUG is also preferred to FBT if the baseline QWB for DRUG value rises by over half. Varying the percentages changing strategies did not affect the results.

\section{Discussion}

When multiple treatments are available, clinicians face choices about which options to recommend. While clinical judgment and patient preference are clearly critical factors, the results here suggest that offering treatment, behavioral or drug, with the option of amending course, produces substantial gains in terms of incontinence episodes avoided and QALYs at relatively low cost. At baseline input values, FBT was more expensive than LBT, but produced greater

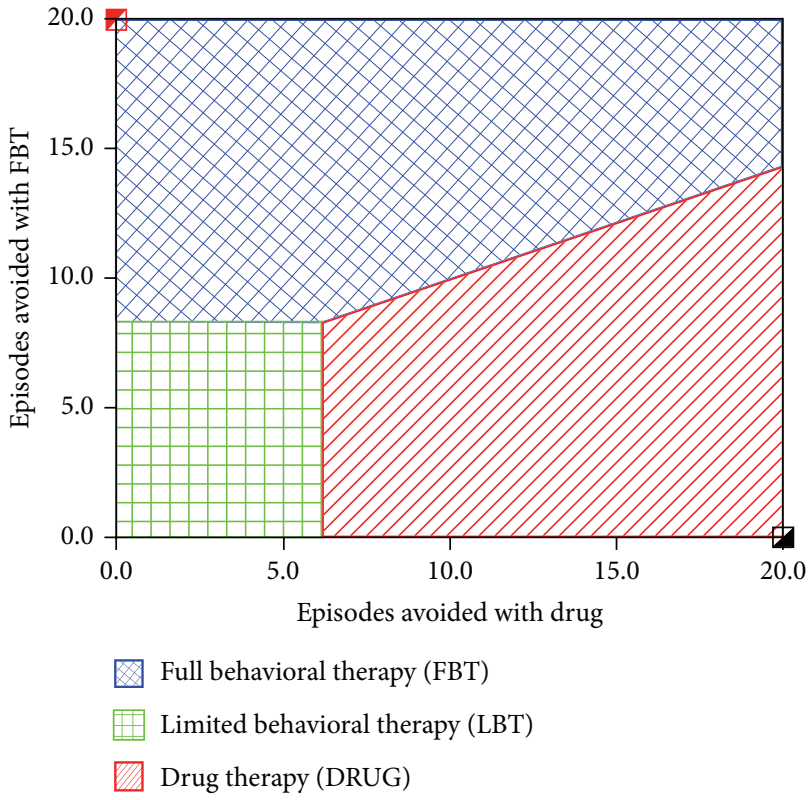

FIGURE 2: Two-way sensitivity analysis on mean episodes avoided drug therapy versus full behavioral therapy.

gains, while FBT was more effective and less costly than DRUG.

DRUG costs needed to fall to $\$ 13$ per month to be cost competitive with FBT. In the US, drug costs vary by payer. Medicare offers provide prescription drug coverage, although the patient often bears some of the cost. For patients who do not purchase medication insurance, some discount pharmacies offer generic drugs at $\$ 4$ per month. Drug prices, furthermore, have fallen given increased competition in the 
market between formulations and the availability of generics and one over-the-counter option. Thus, cost falling to the $\$ 13$ per month to Medicare or patients themselves is plausible. Side-effect rates would also have to fall substantially for DRUG to be competitive in terms of QALYs gained. Each generation of anticholinergic drugs, however, has, with some success, moderated the side-effect profile.

Critically, the sensitivity analysis underscored that only small changes in inputs were required to change the preferred treatment strategy. Thus, no treatment combination dominates under all conditions and all three are reasonable options to pursue.

This paper makes several contributions to the literature. The analysis simulates behavior likely to occur in clinical practices and includes the cost of physician visits, omitted from prior studies [17]. While health-related quality of life relative to incontinence has been addressed in other papers, QALY values are based on correlating scales measuring severity with QALYs, while the approach here estimates QALYS based on an instrument which directly accounts for incontinence issues.

The QALY measure here can be used to compare effectiveness across different medical conditions. For example, the cost per QALY estimates for treating urge incontinence are far lower than those for other conditions such as $\$ 20,171$ per QALY for drug treatments for diabetic patients [28]. The results for urge incontinence also compare well with the widely accepted benchmark of US $\$ 50,000$ to US $\$ 100,000$ per QALY, assumed to represent a good value in health care treatments [29].

The study has certain limitations. Baseline model input values were drawn from a small number of trials restricted to those aged $65+$, residing in the community, and able to provide self-care. Values for crossover from LBT to FBT, rates, and mean reductions were based on a trial using a very limited form of behavioral therapy [21]. Of note is that the QALY estimates here focus only on the impact of incontinence, holding other factors constant. If other comorbid conditions are present and interact with incontinence, QALY changes may be over- or underestimates. The extensive sensitivity analyses employed, however, serve to offset many of these weaknesses.

Pad costs were not included for several reasons. First, if treatment results in a reduction in pad costs, it would favor intervention relative to no intervention as the reduction in pad costs would offset treatment costs. The approach here was to present the least favorable case for treatment. Also, solid data are lacking as to how pad costs would change by strategy. The impact on pad costs, as they are significant to consumers and may affect willingness to pursue treatment, is an important area for research.

The work and findings here are concordant with other studies. Rates of continuation were based on patient reports of their willingness to continue treatment rather than observed behavior. Data from European countries show continuation rates ranging from nine to 18 months [10]. Previous cost analyses related to incontinence include projected savings associated with preventing falls related to urge incontinence. As solid data to quantify this relationship are lacking, cost estimates here exclude them, but are comparable to earlier work once the fall savings values are subtracted [17]. Finally, the cost of DRUG with crossover is 2.6 times more expensive at baseline than FBT. Similar ratios are observed in Europe where pharmacological treatments (without crossover) cost three times that of conservative options (loosely behavioral) in the UK [10].

The majority of patients in the drug trials and all of the patients in the behavioral trials were women; most were white. Results here may not extend to males or to women of other racial and ethnic groups if effects differ greatly from those observed for white women. Certain pathways were not chosen by trial participants and, therefore, were not to be evaluated. These provide areas for further research.

These analyses and the accompanying sensitivity tests strongly suggest that behavioral and/or drug treatment for urge incontinence can improve quality of life for communitydwelling, elderly women at very reasonable costs. The data should encourage clinicians to screen for this condition, often not reported, and develop treatment plans compatible with current guidelines and patient preferences.

\section{Conflict of Interests}

The authors declare that there is no conflict of interests regarding the publication of this paper.

\section{Authors' Contribution}

Victoria L. Phillips performed design, analyses, and paper preparation. Ali Bonakdar Tehrani, Patricia S. Goode, and Kathryn L. Burgio performed analyses and paper preparation. Holly Langmuir performed analyses.

\section{Acknowledgments}

Dr. Patricia S. Goode has been a recipient of a grant from Pfizer in the past and has been a consultant for Astellas. Dr. Kathryn L. Burgio has received research funds and served as a coinvestigator for Pfizer in the past and has served as a consultant for Pfizer, Astellas, and Johnson \& Johnson. The Emory Center for Health in Aging, the Veterans Administration Birmingham/Atlanta Geriatric Research, Education, and Clinical Center (GRECC), and a grant from Pharmacia, Inc. supported this work and had no influence on the analyses or the content of this paper.

\section{References}

[1] K. S. Coyne, M. Kvasz, A. M. Ireland, I. Milsom, Z. S. Kopp, and C. R. Chapple, "Urinary incontinence and its relationship to mental health and health-related quality of life in men and women in Sweden, the United Kingdom, and the United States," European Urology, vol. 61, pp. 88-95, 2012.

[2] W. F. Stewart, J. B. van Rooyen, G. W. Cundiff et al., "Prevalence and burden of overactive bladder in the United States," World Journal of Urology, vol. 20, no. 6, pp. 327-336, 2003.

[3] K. L. Burgio, D. G. Ives, J. L. Locher, V. C. Arena, and L. H. Kuller, "Treatment seeking for urinary incontinence in older 
adults," Journal of the American Geriatrics Society, vol. 42, no. 2, pp. 208-212, 1994.

[4] M. G. Lucas, J. L. H. F. Bosch, F. R. Cruz et al., Guidelines on Urinary Incontinence, European Association of Urology, 2012.

[5] E. A. Gormley, D. J. Lightner, K. L. Burgio et al., Diagnosis and Treatment of Overactive Bladder (Non-Neurogenic) in Adults: AUA/SUFU Guidelines, American Urology Association, 2011.

[6] I. Milsom, P. Abrams, L. Cardozo, R. G. Roberts, J. Thüroff, and A. J. Wein, "How widespread are the symptoms of an overactive bladder and how are they managed? A population-based prevalence study," BJU International, vol. 87, no. 9, pp. 760-766, 2001.

[7] G. Novara, A. Galfano, S. Secco et al., "A systematic review and meta-analysis of randomized controlled trials with antimuscarinic drugs for overactive bladder," European Urology, vol. 54, no. 4, pp. 740-764, 2008.

[8] C. Dumoulin and J. Hay-Smith, "Pelvic floor muscle training versus no treatment for urinary incontinence in women. A Cochrane systematic review," European Journal of Physical and Rehabilitation Medicine, vol. 44, no. 1, pp. 47-63, 2008.

[9] National Institute for Clinical Health and Clinical Excellence, Urinary Incontinence: The Management of Urinary Incontinence in Women, Clinical Guidelines CG40, 2006.

[10] S. Papanicolaou, M. E. Pons, C. Hampel et al., "Medical resource utilisation and cost of care for women seeking treatment for urinary incontinence in an outpatient setting: examples from three countries participating in the PURE study," Maturitas, vol. 52, supplement 2, pp. S35-S47, 2005.

[11] K. L. Burgio, J. L. Locher, P. S. Goode et al., "Behavioral vs drug treatment for urge urinary incontinence in older women: a randomized controlled trial," The Journal of the American Medical Association, vol. 280, no. 23, pp. 1995-2000, 1998.

[12] K. L. Burgio, P. S. Goode, J. L. Locher et al., "Behavioral training with and without biofeedback in the treatment of urge incontinence in older women: a randomized controlled trial," Journal of the American Medical Association, vol. 288, no. 18, pp. 2293-2299, 2002.

[13] A. C. Diokno, R. A. Appell, P. K. Sand et al., "Prospective, randomized, double-blind study of the efficacy and tolerability of the extended-release formulations of oxybutynin and tolterodine for overactive bladder: results of the OPERA trial," Mayo Clinic Proceedings, vol. 78, no. 6, pp. 687-695, 2003.

[14] K. Hesch, "Agents for treatment of overactive bladder: a therapeutic class review," Proceedings (Baylor University. Medical Center), vol. 20, no. 3, pp. 307-314, 2007.

[15] W. J. Sieber, E. J. Groessl, K. M. David, T. G. Ganiats, and R. M. Kaplan, Quality of Well Being Self-Administered (QWB-SA) Scale, 2008.

[16] M. Tzefos, C. Dolder, and J. L. Olin, "Fesoterodine for the treatment of overactive bladder," Annals of Pharmacotherapy, vol. 43, no. 12, pp. 1992-2000, 2009.

[17] L. Hakkaart, P. Verboom, R. Phillips, and M. J. Al, “The cost utility of solifenacin in the treatment of overactive bladder," International Urology and Nephrology, vol. 41, no. 2, pp. 293-298, 2009.

[18] Y. Ko, D. C. Malone, and E. P. Armstrong, "Pharmacoeconomic evaluation of antimuscarinic agents for the treatment of overactive bladder," Pharmacotherapy, vol. 26, no. 12, pp. 1694-1702, 2006.

[19] R.-H. Bödeker, H. Madersbacher, C. Neumeister, and M. Zellner, "Dose escalation improves therapeutic outcome: post hoc analysis of data from a 12 -week, multicentre, doubleblind, parallel-group trial of trospium chloride in patients with urinary urge incontinence," BMC Urology, vol. 10, article 15, 2010.

[20] B. Chughtai, R. Levin, and E. De, "Choice of antimuscarinic agents for overactive bladder in the older patient: focus on darifenacin," Clinical Interventions in Aging, vol. 3, no. 3, pp. 503-509, 2008.

[21] K. L. Burgio, J. L. Locher, and P. S. Goode, "Combined behavioral and drug therapy for urge incontinence in older women," Journal of the American Geriatrics Society, vol. 48, no. 4, pp. 370$374,2000$.

[22] Consumers Union, Evaluating Prescription Drugs Used to Treat: Overactive Bladder Comparing Effectiveness, Safety, and Price, 2010.

[23] R. U. Anderson, D. Mobley, B. Blank, D. Saltzstein, J. Susset, and J. S. Brown, "Once daily controlled versus immediate release oxybutynin chloride for urge urinary incontinence. OROS Oxybutynin Study Group," The Journal of Urology, vol. 161, no. 6, pp. 1809-1812, 1999.

[24] N. R. Zinner, A. Mattiasson, and S. L. Stanton, "Efficacy, safety, and tolerability of extended-release once-daily tolterodine treatment for overactive bladder in older versus younger patients," Journal of the American Geriatrics Society, vol. 50, no. 5, pp. 799-807, 2002.

[25] S. Lee, B. Malhotra, D. Creanga, M. Carlsson, and P. Glue, "A meta-analysis of the placebo response in antimuscarinic drug trials for overactive bladder," BMC Medical Research Methodology, vol. 9, article 55, 2009.

[26] R. A. Appell, P. Sand, R. Dmochowski, R. Anderson, and N. Zinner, "Prospective randomized controlled trial of extendedrelease oxybutynin chloride and tolterodine tartrate in the treatment of overactive bladder: results of the OBJECT study," Mayo Clinic Proceedings, vol. 76, no. 4, pp. 358-363, 2001.

[27] P. Siami, L. S. Seidman, and D. Lama, "A multicenter, prospective, open-label study of tolterodine extended-release $4 \mathrm{mg}$ for overactive bladder: the speed of onset of therapeutic assessment trial (STAT)," Clinical Therapeutics, vol. 24, no. 4, pp. 616-628, 2002.

[28] S. L. Tunis, M. E. Minshall, M. St. Charles, B. J. Pandya, and R. W. Baran, "Pioglitazone versus rosiglitazone treatment in patients with type 2 diabetes and dyslipidemia: cost-effectiveness in the US," Current Medical Research and Opinion, vol. 24, no. 11, pp. 3085-3096, 2008.

[29] A. C. Haddix, S. M. Teutsch, and P. S. Corso, Prevention Effectiveness: A Guide to Decision Analysis and Economic Evaluation, Oxford University Press, Oxford, UK, 2nd edition, 2003. 


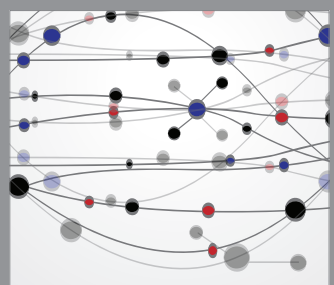

The Scientific World Journal
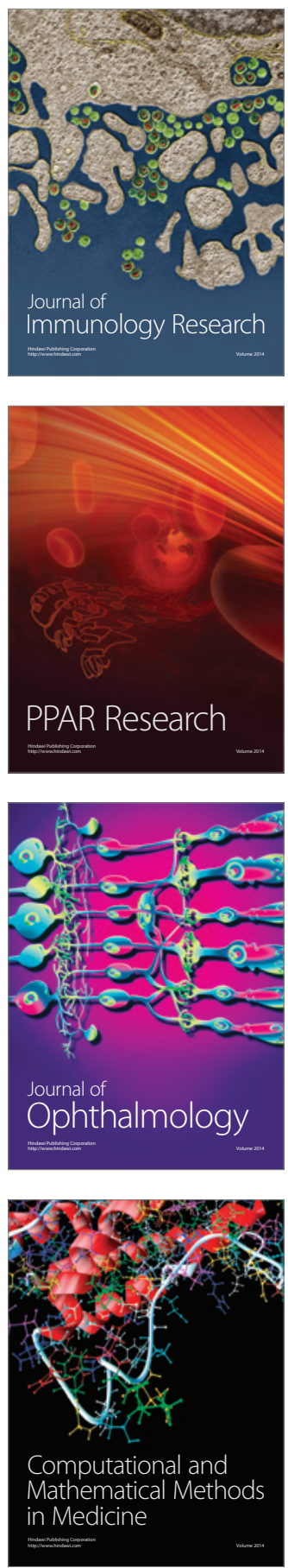

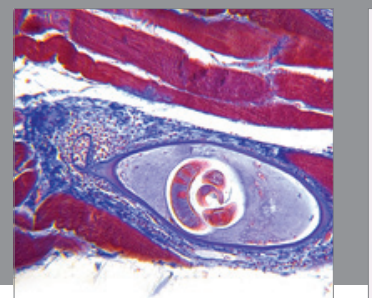

Gastroenterology

Research and Practice
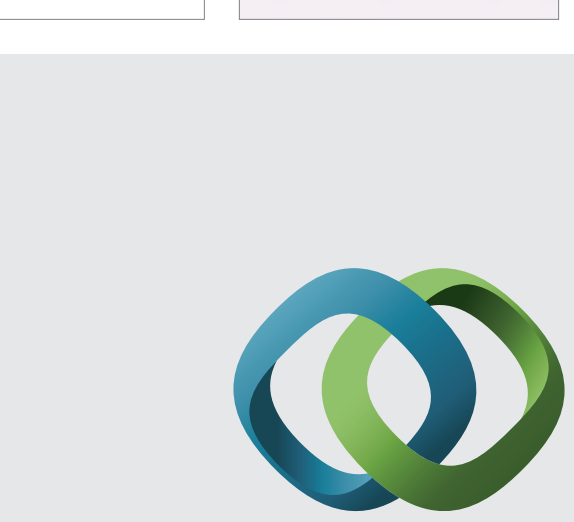

\section{Hindawi}

Submit your manuscripts at

http://www.hindawi.com
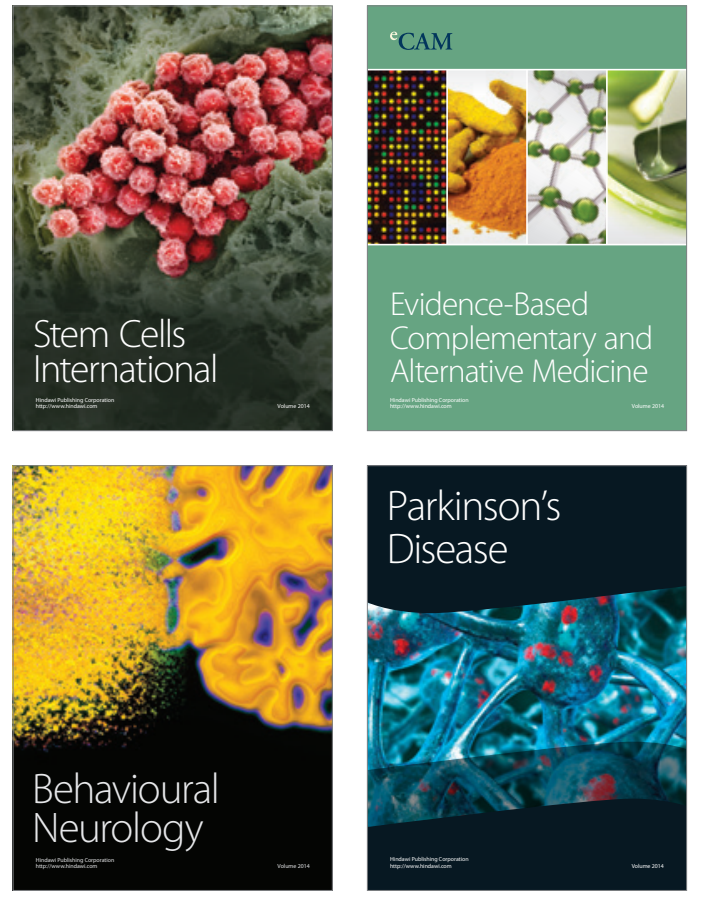
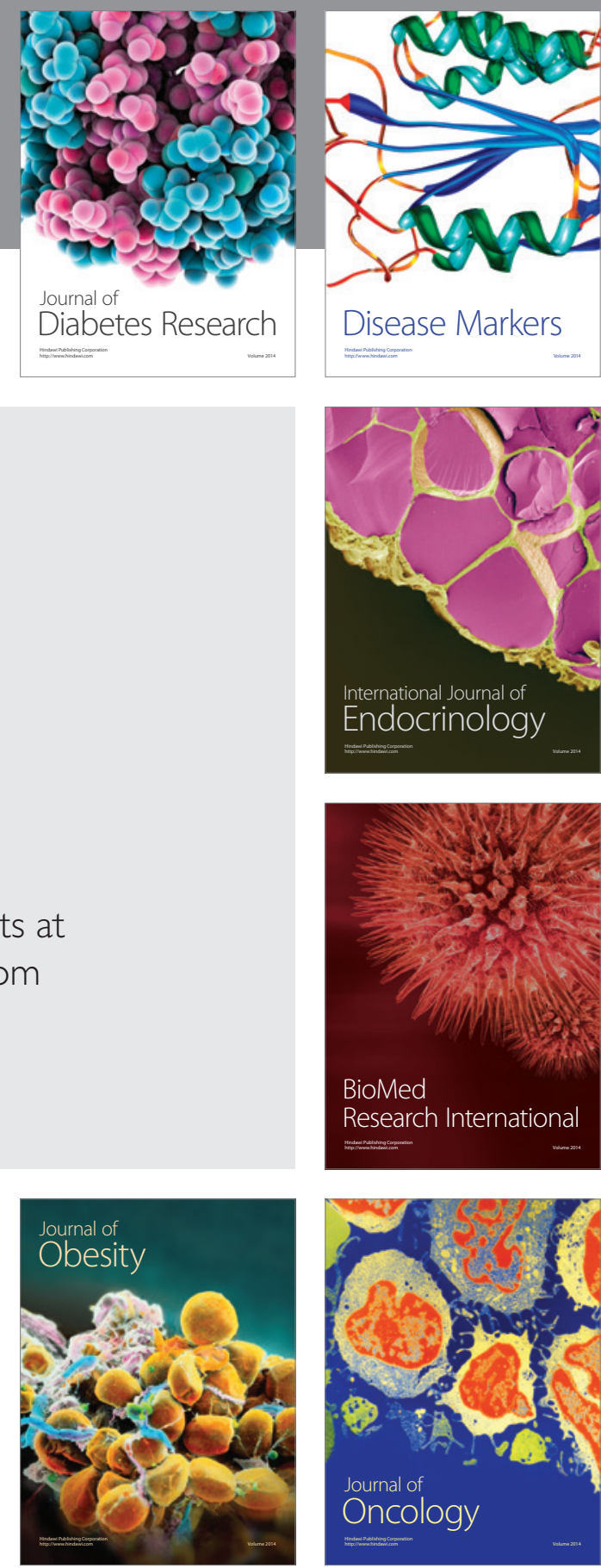

Disease Markers
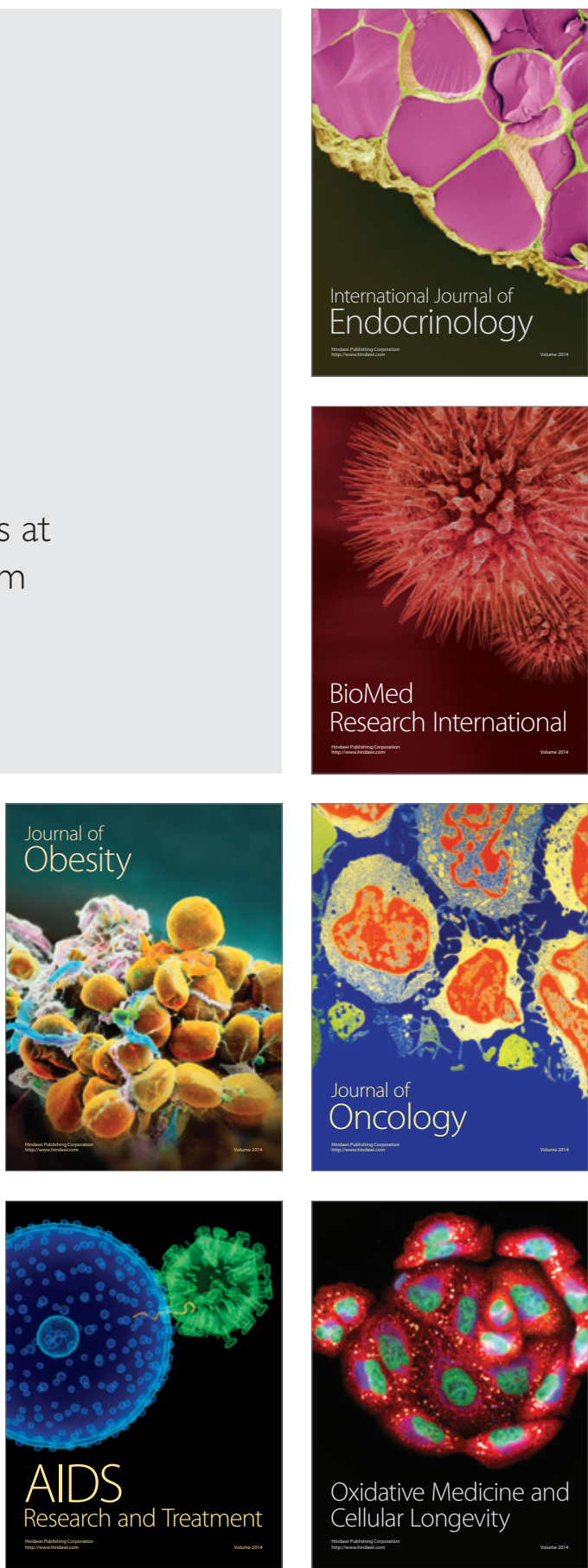